\title{
HIGH-PERFORMANCE, LATTICE-MISMATCHED InGaAs/InP MONOLITHIC INTERCONNECTED MODULES (MIMS)
}

Navid S. Fatemi, David M. Wilt, Richard W. Hoffman, Jr., Mark S. Stan, Victor G. Weizer, Phillip P. Jenkins, Osman S. Khan, Christopher S. Murray, David Scheiman, and David Brinker

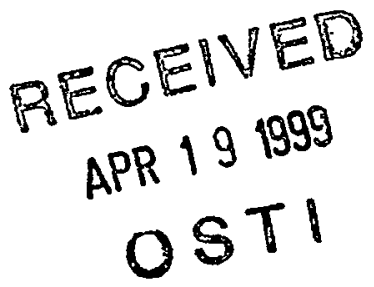

\section{NOTICE}

This report was prepared as an account of work sponsored by the United States Government. Neither the United States, nor the United States Department of Energy, nor any of their employees, nor any of their contractors, subcontractors, or their employees, makes any warranty, express or implied, or assumes any legal liability or responsibility for the accuracy, completeness or usefulness of any information, apparates, product or process disclosed, or represents that its use would not infringe privately owned rights. 


\section{DISCLAIMER}

This report was prepared as an account of work sponsored by an agency of the United States Government. Neither the United States Government nor any agency thereof, nor any of their employees, make any warranty, express or implied, or assumes any legal liability or responsibility for the accuracy, completeness, or usefulness of any information, apparatus, product, or process disclosed, or represents that its use would not infringe privately owned rights. Reference herein to any specific commercial product, process, or service by trade name, trademark, manufacturer, or otherwise does not necessarily constitute or imply its endorsement, recommendation, or favoring by the United States Government or any agency thereof. The views and opinions of authors expressed herein do not necessarily state or reflect those of the United States Government or any agency thereof. 


\section{DISCLAIMER}

Portions of this document may be illegible in electronic image products. Images are produced from the best available original document. 


\title{
High-Performance, Lattice-Mismatched InGaAs/InP Monolithic Interconnected Modules (MIMs)
}

\author{
Navid S. Fatemi ${ }^{1}$, David M. Wilt ${ }^{2}$, Richard W. Hoffman, Jr. ', \\ Mark A. Stan ${ }^{1}$, Victor G. Weizer ${ }^{1}$, Phillip P. Jenkins ${ }^{1}$, Osman S. Khan ${ }^{1}$, \\ Christopher S. Murray ${ }^{3}$, David Scheiman ${ }^{2}$ and David Brinker ${ }^{2}$

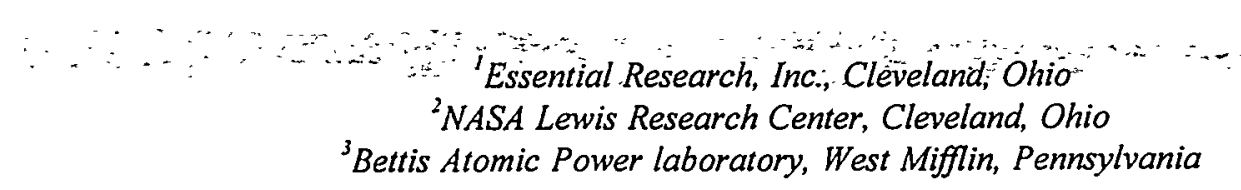

\begin{abstract}
High performance, lattice-mismatched $\mathrm{p} / \mathrm{n}$ InGaAs/InP monolithic interconnected module (MIM) structures were developed for thermophotovoltaic (TPV) applications. A MIM device consists of several individual InGaAs photovoltaic (PV) cells series-connected on a single semi-insulating (S.I.) InP substrate. Both interdigitated and conventional (i.e., non-interdigitated) MIMs were fabricated. The energy bandgap (Eg) for these devices was $0.60 \mathrm{eV}$. A compositionally step-graded InPAs bufferwas used to accommodate a lattice mismatch of $1.1 \%$ between the active InGaAs cell structure and the InP substrate. $1 \times 1-\mathrm{cm}, 15-\mathrm{cell}, 0.60-\mathrm{eV}$ MIMs demonstrated an open-circuit voltage (Voc) of $5.2 \mathrm{~V}(347 \mathrm{mV}$ per cell) and a fill factor of $68.6 \%$ at a short-circuit current density (Jsc) of $2.0 \mathrm{~A} / \mathrm{cm}^{2}$, under flashlamp testing. The reverse saturation current density (Jo) was $1.6 \times 10^{-6} \mathrm{~A} / \mathrm{cm}^{2}$. Jo values as low as $4.1 \times 10^{-7} \mathrm{~A} / \mathrm{cm}^{2}$ were also observed with a conventional planar cell geometry.
\end{abstract}

\section{INTRODUCTION}

Monolithic interconnected module (MIM) devices for thermophotovoltaic (TPV) applications have been under development for the past several years [1-6]. In a MIM, small area InGaAs photovoltaic (PV) cells are connected in series monolithically, on a semi-insulating (S.I.) InP substrate. This results in the formation of a module with a very desirable power profile, i.e., a high-voltage/low-current configuration. There are other advantages to a MIM device as compared to conventional planar devices. A prominent advantage of MIM is its ability to efficiently recuperate (recycle) the incident non-convertible infrared (IR) radiation. 
Optical recuperation is mandatory to achieve high efficiencies in a TPV system. Conventionally, separate front surface filtering elements, such as dielectric stack bandpass, or plasma, or tandem filters are used in front of a PV cell to accomplish optical recuperation. These elements, however, attenuate the useful in-band radiation reaching the PV cell. As a result, the cell's output power density is diminished. They not only add complexity to the design of a TPV system, but they also tend to absorb both in-band and out-of-band radiation.

An alternative approach to optical recuperation is the use of a back surface reflector (BSR)._A highly IR-reflective material such as gold can be used on the back side of the semi-insulating InP wafer to accomplish this task. As shown schematically in Figure 1, the fabrication of MIM requires the use of a semi-insulating InP substrate. Unlike doped InP substrates, S.I. InP is transparent to infrared (IR) radiation. Radiation with wavelengths greater than the device bandedge wavelength (i.e., $\lambda \mathrm{g} \sim 2 \mu \mathrm{m}$ ) can be reflected back to the TPV radiator via the BSR. This reflected energy can be recuperated by the radiator, thus, reducing the energy input to the heat source.

In fact, spectral utilization (SU) factors greater than $70 \%$ have been measured for a MIM with a BSR, and a bandgap of $0.60 \mathrm{eV}$ [7]. The SU factor is defined as the abovebandgap absorbed energy in the active device layers divided by the total absorbed energy in the structure. This SU factor is greater than what has been observed with the most advanced filtering options currently available (i.e., SU of $<70 \%$ ) [8]. The use of a BSR in a MIM configuration, therefore, eliminates the need to use separate front surface filters.

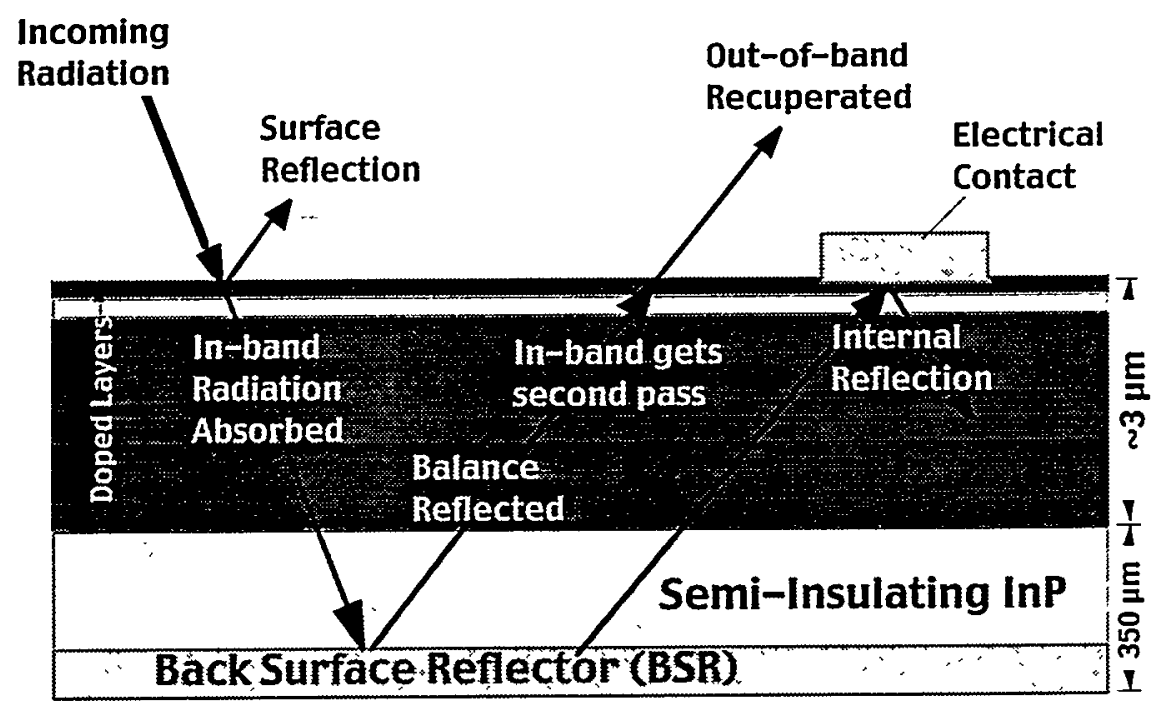

Figure 1.-Optical recuperation (recycling) in a MIM structure.

Another advantage to a MIM design is that both the negative and positive electrical connections are fabricated on the top side of the module, thereby simplifying the array design, interconnection, and thermal management. The completed device may be soldered directly onto the array substrate/heat sink without having to provide electrical 
isolation. Individual MIMs can then be connected in series or parallel configurations by welding or bonding of metallic interconnect ribbons to adjacent busbars. A photograph of an array, comprised of twelve $1 \times 1-\mathrm{cm}$ conventional MIMs, interconnected by this process is shown in Figure 2.

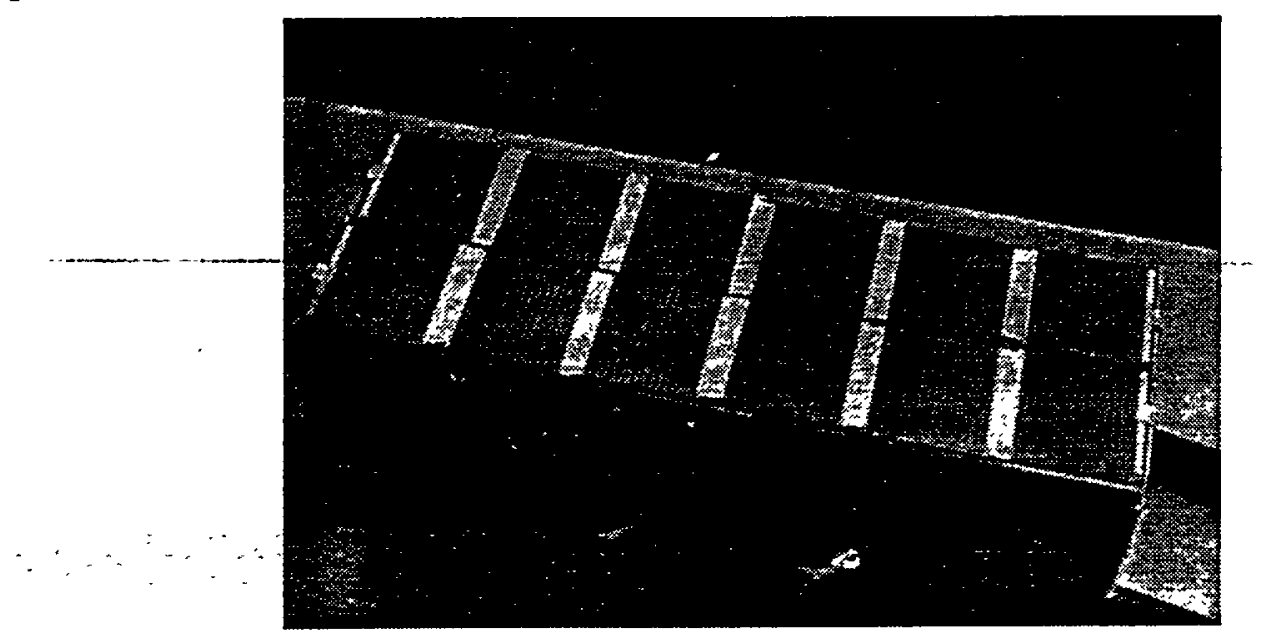

Figure 2.-Photograph of an array of twelve 1x1-cm MIMs on a heatsink.

In a TPV system, the bandgap of the PV device is ideally selected to match the peak intensity of the radiator spectral power density at the operating temperature. At low to moderate radiator temperatures (i.e., $1200-1500 \mathrm{~K}$ ), the PV cells used normally have bandgap values of $0.74 \mathrm{eV}$ or smaller. The most commonly studied devices are the lattice-matched InGaAs-on-InP and GaSb cells, with bandgaps of 0.74 and $0.73 \mathrm{eV}$, respectively. The spectral response of the PV cells with lower bandgaps, however, are better matched to the graybody spectral power density profile for low to moderate radiator temperatures. Examples of cells with lower bandgaps are lattice-mismatched InGaAs-on-InP and lattice-matched InGaAsSb-on-GaSb.

In Figure 3, for example, the spectral response for two high-quality InGaAs/InP MIM devices with bandgaps of 0.74 and $0.60 \mathrm{eV}$ are overlaid on top of the spectral power density curve for a blackbody at a temperature of $1500 \mathrm{~K}$. As shown in the figure, the response of the lattice-mismatched device with $\mathrm{Eg}=0.60 \mathrm{eV}$ is far better matched to the peak intensity of the blackbody power curve. As a result, in the example shown, the output current of the $0.60-\mathrm{eV}$ device is more than $80 \%$ greater than the output current for the $0.74-\mathrm{eV}$ device. 


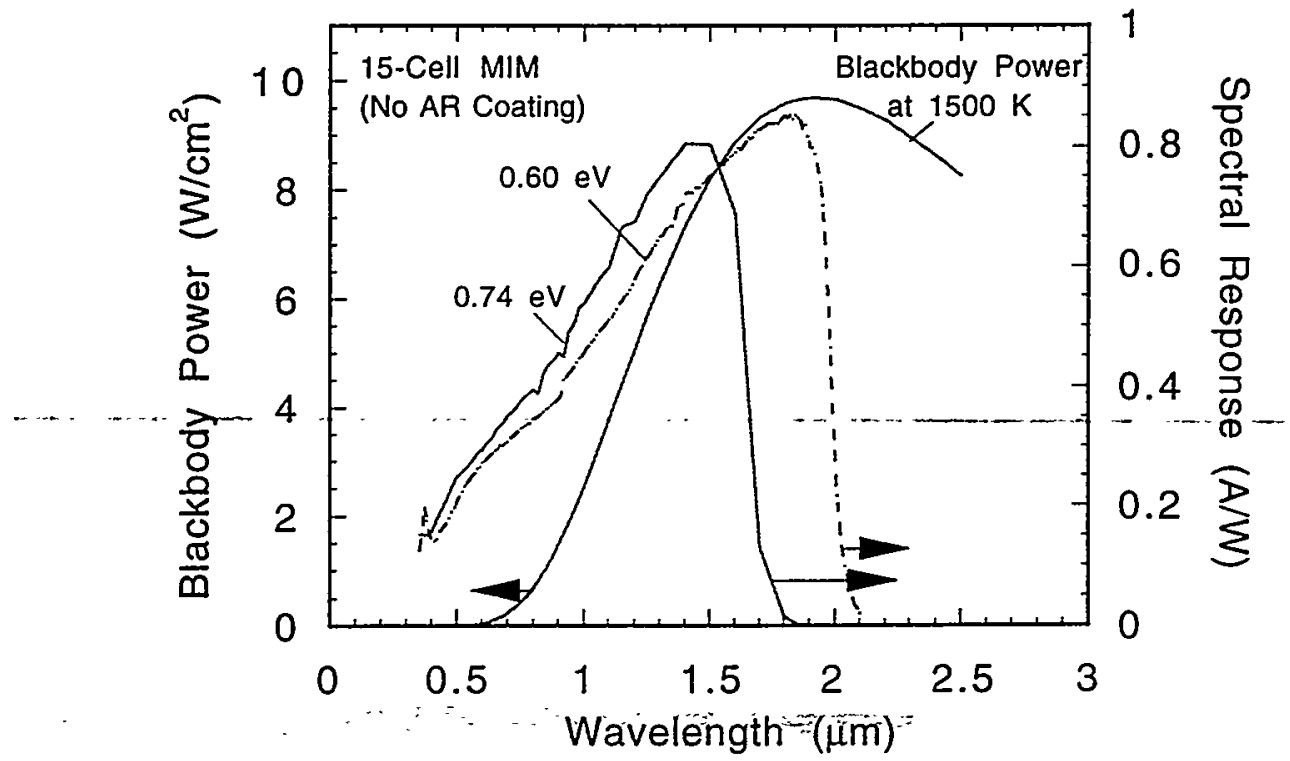

Figure 3.-Measured spectral response data for 15-cell InGaAs/InP MIMs, with Eg $=0.60 \mathrm{eV}$ and $0.74 \mathrm{eV}$ (with no anti-reflection coating), and the blackbody spectral power density curve at $1500 \mathrm{~K}$.

We have fabricated and tested lattice-mismatched $\mathrm{p} / \mathrm{n}$ InGaAs/InP MIMs, grown by organo-metallic vapor phase epitaxy (OMVPE). Both interdigitated [4] and conventional (non-interdigitated) $[1-3,5]$ MIMs were developed. These structures had a bandgap of $0.60 \mathrm{eV}$. High performance MIMs were developed using a compositionally step-graded InPAs buffer to accommodate a lattice mismatch of $1.1 \%$ between the active InGaAs cell structure and the InP substrate. In what follows, we will present data regarding the electrical performance of these devices.

\section{MIM DESIGN AND STRUCTURE}

Two MIM geometries were fabricated and tested. The first was the conventional design that has been under development jointly by Essential Research and NASA Lewis, and also independently by Spire Corporation, for the past several years [1-3, 5-6]. The second was the interdigitated design that was under development at NASA Lewis and refined independently at the National Renewable Energy Laboratory (NREL) [4].

The $1 \times 1-\mathrm{cm}$ and $2 \times 2-\mathrm{cm}$ conventional MIM designs had 15 and 30 cells interconnected in series, respectively. Each individual cell was approximately $550 \mu \mathrm{m}$ wide and either 1 or $2 \mathrm{~cm}$ long. The $1 \times 1$-inch $(2.54 \times 2.54-\mathrm{cm})$ interdigitated design had 23 cells interconnected in series. Each individual cell was approximately $975 \mu \mathrm{m}$ wide and $2.54 \mathrm{~cm}$ long. A photograph of several conventional MIMs as processed on 2-inch InP wafers are shown in Figure 4. 


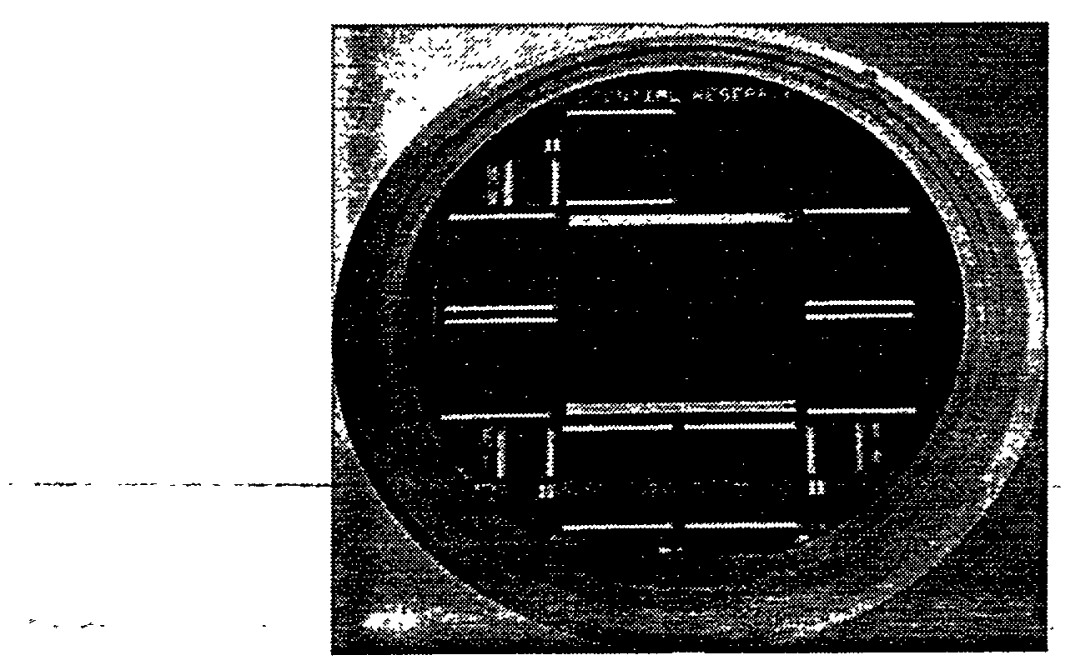

Figure 4.-Photograph of a 2-inch diameter Semi-insulating InP wafer with one 30-cell $(2 \times 2-\mathrm{cm})$ and seven 15-cell $(1 \times 1-\mathrm{cm})$ conventional MIMs.

The conventional and interdigitated MiMs had very similar structures. A schematic cross-sectional view of a MIM structure is shown in Figure 5. The advantage of the interdigitated MIM is that the design allows for the use of a thinner, lower doped lateral conduction layer (LCL). Typically, the LCL layer for the interdigitated structure was $0.25 \mu \mathrm{m}$ thick with a carrier concentration in the low $10^{18} \mathrm{~cm}^{-3}$ range. In contrast, the LCL layer for the conventional structure was $1.0 \mu \mathrm{m}$ thick with a carrier concentration in the low $10^{19} \mathrm{~cm}^{-3}$ range. Thinner and lower doped semiconductor layers show lower free-carrier absorption (FCA). Lower FCA results in more efficient optical recuperation via the BSR $[2,5]$.

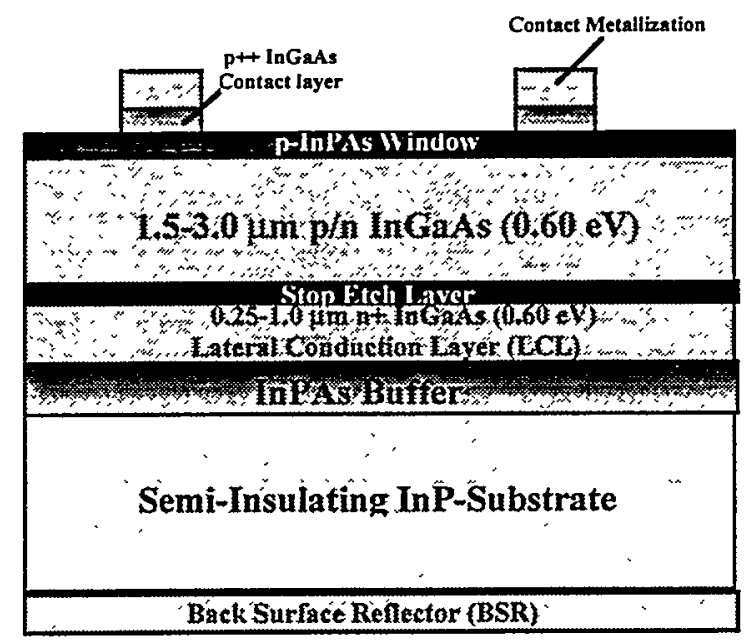

Figure 5.-Schematic cross-sectional view of InGaAs/InP MIM.

The advantage of the conventional design is that it is less sensitive to the minority carrier diffusion length in the base region. The base layer of the device can be thinner than optimum in this design (i.e., $1.5 \mu \mathrm{m}$ versus $3.0 \mu \mathrm{m}$ ). As a result, the in-band photons impinging on the device are not completely absorbed in the first pass through 
the device. Therefore, the unabsorbed portion of the usable photons can reflect off the BSR and have a second pass through the active regions of the device. This process forces the carrier generation to occur closer to the $\mathrm{p} / \mathrm{n}$ junction. The high doping level in the InGaAs LCL layer effectively increases the optical bandgap of this layer (i.e., the Burnstien-Moss shift) to allow the shorter wavelength convertible radiation to pass through to the BSR with negligible absorption.

Recent Monte-Carlo photonic modeling, being presented at this conference [9], suggests that the processing techniques used can have a significant effect on the amount of photons that can be recuperated at the radiator: Four areas of particular interest are the specular/diffused reflectance of the BSR, light trapping due to surface features (i.e., isolation trenches), the reflectance of the electrical metallization at the metalsemiconductor interface, and IR absorption in the anti-reflective coating.

\section{RESULTS}

External quantum efficiency (QE) and high-intensity illumination current versus voltage (I-V) measurements were performed to characterize the MIMs. We will present data for $\mathrm{p} / \mathrm{n}$ InGaAs/InP $0.60-\mathrm{eV}$ lattice-mismatched conventional and interdigitated MIMs, as well as some data for conventional planar (i.e., non-MIM) one-junction devices.

\section{External Quantum Efficiency (QE) Data}

Initially, planar one-junction conventional $0.60-\mathrm{eV} \mathrm{p} / \mathrm{n}$ InGaAs/InP cells were fabricated and tested. Excellent current collection over a wide range of wavelengths (i.e., $0.45-2.0 \mu \mathrm{m}$ ) was measured with these devices. This data is shown in Figure 6 . Note that the cell did not have an anti-reflection (AR) coating. The estimated internal quantum efficiency was near unity near the bandedge. This result demonstrates the effectiveness of the buffer layer, grown between the $\mathrm{InP}$ substrate and the active regions of the $0.60-\mathrm{eV}$ InGaAs device, to limit the propagation of threading dislocations from the buffer-InP interface to the top active layers of the device.

The QE data for both conventional and interdigitated MIM structures were similar to the data measured for the planar cells. The main difference between the planar cell structure and the MIM structure was that the latter had an extra LCL layer. The QE plots for conventional and interdigitated MIM structures are illustrated in Figure 7. Note that the MIMs did not have any AR coating. 


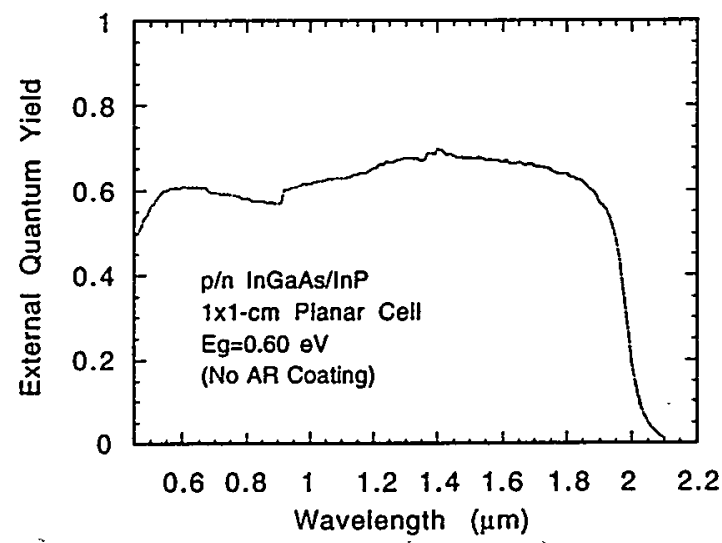

Figure 6.-External quantum efficiency data for a conventional planar cell with $\mathrm{Eg}=0.60 \mathrm{eV}$ (No AR coating).
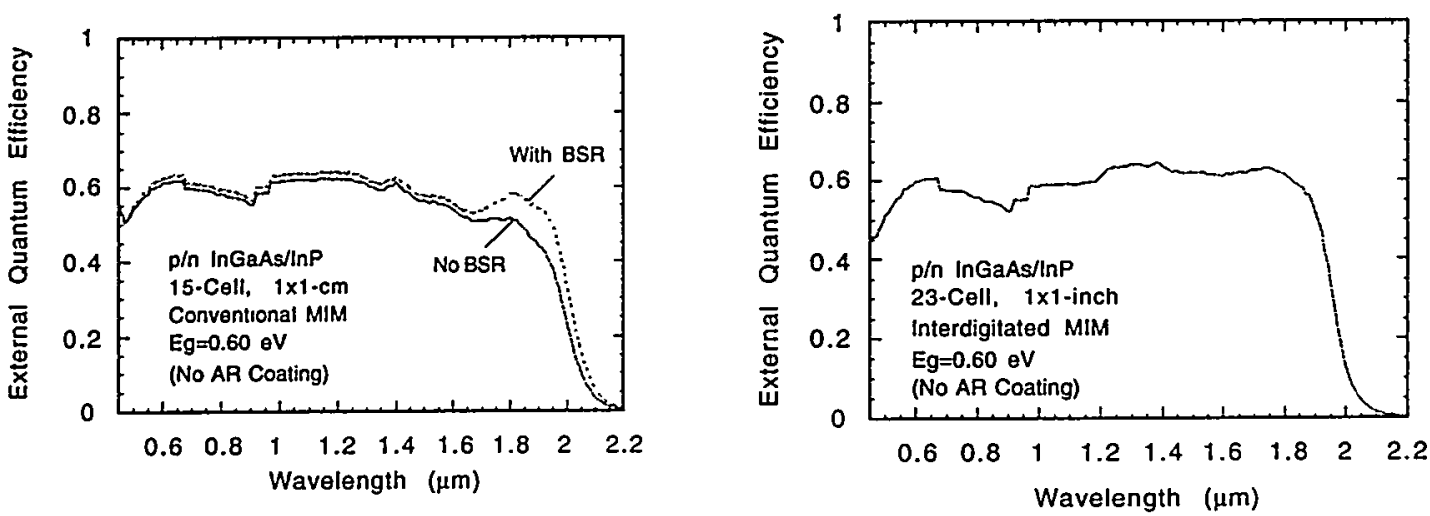

Figure 7.-External quantum efficiency data for a conventional MIM structure (left), and an interdigitated MIM structure (right), with $\mathrm{Eg}=0.60 \mathrm{eV}$ (No AR coating).

The QE data for the conventional MIM also shows the effect of the BSR in improving the current collection, especially near the bandedge. As mentioned earlier, this is due to increased absorption in the active layers, during the second pass, after reflecting off the BSR.

\section{Current-Voltage (I-V) Data}

The MIMs were tested under high-intensity illumination, using a large-areapulsed solar simulator (LAPSS), to assess their performance under simulated operating conditions. The results for the variation in the open-circuit voltage (Voc) and fill factor (FF) with the short-circuit current density (Jsc), for $0.60-\mathrm{eV}$ conventional and interdigitated MIMs are given in Figures 8 and 9, respectively. 

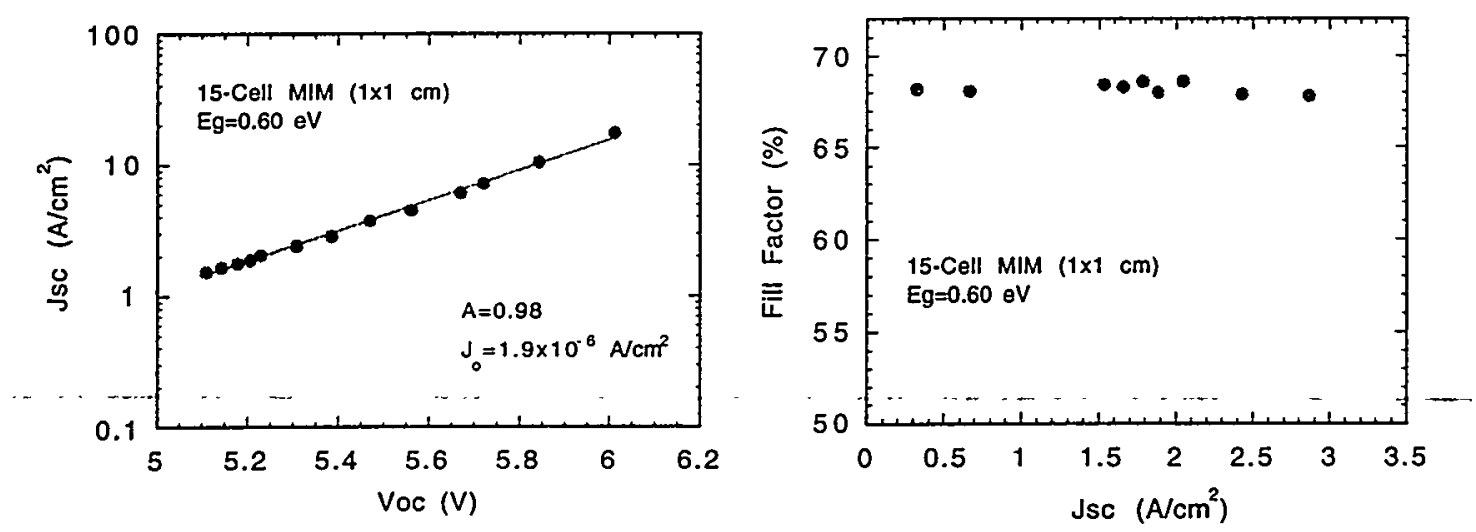

Figure 8.-Variation of Voc (left) and FF (right) with Jsc for a conventional 15-cell InGaAs/InP MIM, with $\mathrm{Eg}=0.60 \mathrm{eV}$.
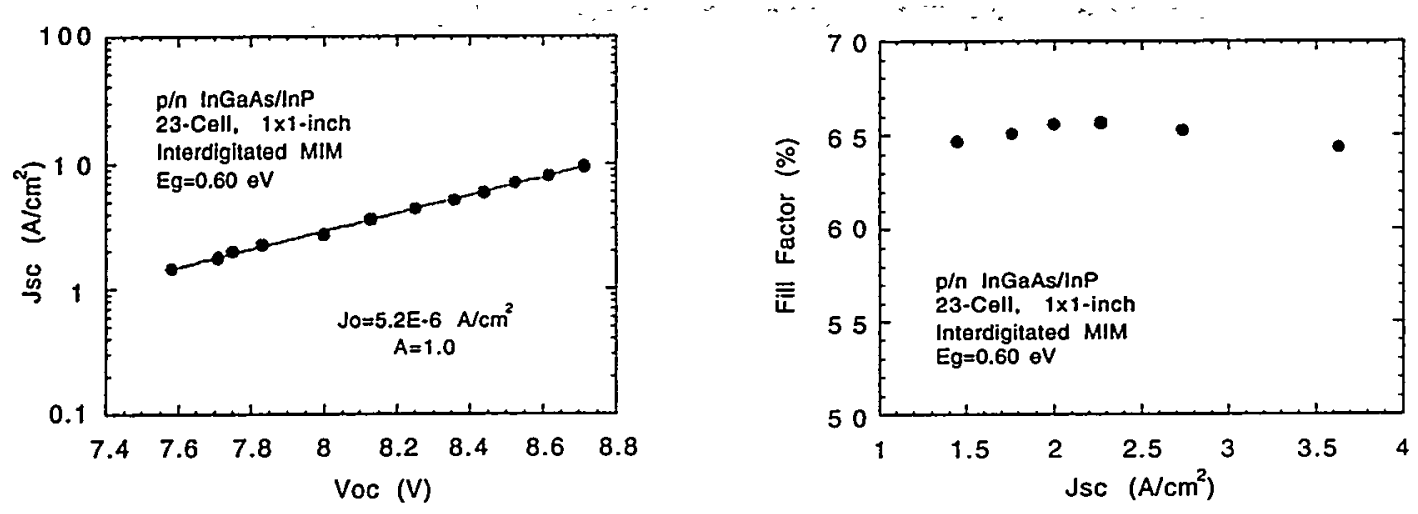

Figure 9.-Variation of Voc (left) and FF (right) with Jsc for a 23-cell interdigitated InGaAs/InP MIM, with $\mathrm{Eg}=0.60 \mathrm{eV}$.

As shown in the figures, the diode ideality factor (A) for both structures was unity. The reverse saturation current density (Jo) was calculated to be in the range of $1.9-5.2 \times 10^{-6} \mathrm{~A} / \mathrm{cm}^{2}$. This range of Jo values is more than an order of magnitude lower than the best results reported in the literature for an InGaAs/InP cell with $\mathrm{Eg}=0.60 \mathrm{eV}$ [10]. We have also observed Jo values, as low as $4.1 \times 10^{-7} \mathrm{~A} / \mathrm{cm}^{2}$ for $1 \times 1-\mathrm{cm}$ planar (non-MIM) p/n InGaAs/InP 0.60-eV cells.

For both device structures, they remained at or above $65 \%$ for the short-circuit current densities up to about $3 \mathrm{~A} / \mathrm{cm}^{2}$. The results for the $\mathrm{I}-\mathrm{V}$ data presented suggest that the buffering technique used to grow the $0.60-\mathrm{eV}$ lattice-mismatched InGaAs on InP was effective in preventing the majority of the dislocations created at the cell-substrate interface from threading up into the active regions of the cell structure. 
From the QE and I-V data presented above, we calculated the expected electrical performance of the MIMs in a TPV system. The graybody radiator was assumed to have an emissivity of 0.9 and a view factor of 0.9 . The graybody radiator temperature was varied from 1100 to $1500 \mathrm{~K}$, and the cell temperature was assumed to be constant at $25^{\circ} \mathrm{C}$. For comparison, the performance of a conventional MIM with a bandgap of $0.74 \mathrm{eV}$ was also calculated.

The short-circuit current density, Jsc, was calculated by integrating the measured spectral response times the spectral graybody power density over the wavelength range of 0.35 to $2.1 \mu \mathrm{m}$. The illuminated I-V data measured by the LAPSS was then used to determine Voc and FF at the Jsc point calculated above. The output power was the product of Voc, FF, and Isc. The results for a 1x1-inch 23-cell interdigitated $(\mathrm{Eg}=0.60 \mathrm{eV})$ and two $1 \times 1-\mathrm{cm} 15$-cell conventional MIMs $(\mathrm{Eg}=0.60$ and $0.74 \mathrm{eV})$ are shown in Table I.

TABLE 1.-Electrical performance of $\mathrm{p} / \mathrm{n}$ InGaAs/InP MIMs under simulated TPV conditions.

\begin{tabular}{|c|c|c|c|c|c|c|}
\hline MIM Device & $\mathrm{Eg}(\mathrm{eV})$ & $\begin{array}{c}\text { Radiator } \\
\text { Temperature } \\
\text { (K) }\end{array}$ & $\begin{array}{c}\text { Jsc } \\
\left(\mathrm{A} / \mathrm{cm}^{2}\right)\end{array}$ & $\begin{array}{l}\text { Voc }(V) / \text { Voc } \\
\text { per Cell (V) }\end{array}$ & $\begin{array}{c}\text { Fill Factor } \\
(\%)\end{array}$ & $\begin{array}{c}\text { Power (W)/ } \\
\text { Power Density } \\
\left(W / \mathrm{cm}^{2}\right)\end{array}$ \\
\hline \multirow{3}{*}{$\begin{array}{l}\text { Interdigitated } \\
(2.54 \times 2.54 \mathrm{~cm})\end{array}$} & \multirow{3}{*}{0.60} & 1100 & 0.66 & $7.30 / 0.317$ & 63.5 & $0.62 / 0.13$ \\
\hline & & 1300 & 2.26 & $7.83 / 0.340$ & 65.7 & $2.36 / 0.51$ \\
\hline & & 1500 & 5.83 & $8.43 / 0.367$ & 61.0 & $6.10 / 1.31$ \\
\hline \multirow{3}{*}{$\begin{array}{l}\text { Conventional } \\
(1 \times 1 \mathrm{~cm})\end{array}$} & \multirow{3}{*}{0.60} & 1100 & 0.69 & $4.69 / 0.313$ & 68.1 & $0.12 / 0.15$ \\
\hline & & 1300 & 2.36 & $5.26 / 0.351$ & 68.3 & $0.45 / 0.57$ \\
\hline & & 1500 & 6.00 & $5.64 / 0.376$ & 64.9 & $1.15 / 1.46$ \\
\hline \multirow{4}{*}{$\begin{array}{l}\text { Conventional } \\
(1 \times 1 \mathrm{~cm})\end{array}$} & \multirow{4}{*}{0.74} & 1100 & 0.27 & $5.70 / 0.380$ & 77.1 & $0.063 / 0.079$ \\
\hline & & 1300 & 1.13 & $6.30 / 0.420$ & 76.1 & $0.28 / 0.36$ \\
\hline & & 1500 & 3.30 & $6.66 / 0.444$ & 75.0 & $0.86 / 1.10$ \\
\hline & & 1700 & 7.69 & $6.95 / 0.463$ & 71.3 & $2.00 / 2.54$ \\
\hline
\end{tabular}

The data in the above table shows that relatively large electrical output power, in the range of $0.45-1.15$ watts, can be obtained with $0.60-\mathrm{eV}, 1 \times 1-\mathrm{cm}$ MIMs at moderate radiator temperatures $(1300-1500 \mathrm{~K})$. The better matching of the $0.60-\mathrm{eV}$ versus $0.74-\mathrm{eV}$ device response to the blackbody peak radiation curve (see Figure 3), and the high quality of the lattice-mismatched devices, result in significantly higher output power for the lower bandgap devices. In the temperature range of $1300-1500 \mathrm{~K}$, for example, the $0.74-\mathrm{eV}$ MIMs produced only about $62-75 \%$ of the power that the 
$0.60-\mathrm{eV}$ MIMs produced. It should be noted that the structure of the MIMs with $\mathrm{Eg}=0.60 \mathrm{eV}$ was optimized for operation with a radiator temperature of about $1300 \mathrm{~K}$, whereas the structure of the MIMs with $\mathrm{Eg}=0.74 \mathrm{eV}$ was optimized for operation with a radiator temperature of $1500 \mathrm{~K}$.

We believe that the data presented in Table 1 are practical values that we can expect to observe under actual TPV conditions. Specifically, in a separate experiment we have demonstrated that our calculated data for the 0.74-eV MIMs are in close agreement with the measured experimental data taken under actual TPV conditions. An array of 12, 0.74-eV, $1 \times 1=\mathrm{cm}$ MIMS (see Figure-2) was coupled to a combustion heated $\mathrm{SiC}$ radiator operated at $1300 \mathrm{~K}$, resulting in measured Voc and Isc values $6 \%$ higher and $2 \%$ lower than the calculated values, respectively.

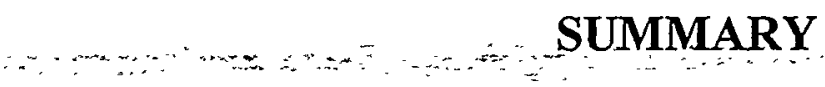

The results presented in this work are summarized below:

1. We have fabricated and tested lattice-mismatched $\mathrm{p} / \mathrm{n} \operatorname{InGaAs} / \mathrm{InP}$ monolithic interconnected modules (MIMs), with a bandgap of $0.60 \mathrm{eV}$. These devices had a gold back surface reflector (BSR) that is used to recuperate non-absorbed photons at the radiator, increasing TPV system efficiency.

2. Both interdigitated and conventional MIM designs were fabricated. The $1 \times 1-\mathrm{cm}$ and $2 \times 2$-cm conventional MIMs had 15 and 30 cells interconnected in series, respectively. The $1 \times 1$-inch $(2.54 \times 2.54-\mathrm{cm})$ interdigitated MIMs had 23 cells interconnected in series.

3. The external quantum efficiency data for the lattice-mismatched structures showed very good collection efficiency. The internal $\mathrm{QE}$ was estimated to be near unity close to the bandedge.

4. MIM devices were tested under high-intensity illumination. The diode ideality factor (A) and the reverse saturation current density (Jo) for the MIMs with $\mathrm{Eg}=0.60 \mathrm{eV}$ were near or at unity, and $1.9-5.2 \times 10^{-6} \mathrm{~A} / \mathrm{cm}^{2}$, respectively. Lower Jo values (i.e., $4.1 \times 10^{-7} \mathrm{~A} / \mathrm{cm}^{2}$ ) were also observed for the planar (nonMIM) structures. The fill factor values remained at or above $65 \%$ for shortcircuit current densities up to $3 \mathrm{~A} / \mathrm{cm}^{2}$.

5. From the measured $\mathrm{QE}$ and $\mathrm{I}-\mathrm{V}$ data, the expected output power for the $0.60-\mathrm{eV}$ devices, when coupled to a graybody radiator (emissivity of 0.9 and view-factor of 0.9) was calculated. Relatively large power densities, in the range of $0.45-1.15 \mathrm{~W}$, were calculated for a radiator temperature range of $1300-1500 \mathrm{~K}$. 


\section{REFERENCES}

[1] N. S. Fatemi, D. M. Wilt, P.P. Jenkins, V.G. Weizer, R.W. Hoffman, C.S. Murray, D. Scheiman, D. Brinker, and D. Riley, "InGaAs Monolithic Interconnected Modules (MIMs)," Twenty Sixth Photovoltaic Specialists Conference (PVSC), p. 799, 1997.

[2] D. M. Wilt, N. S. Fatemi, P.P. Jenkins, V.G. Weizer, R.W. Hoffman, R.K. Jain, C.S. Murray, and D. Riley, "Electrical and Optical Performance Characteristics of $0.74 \mathrm{eV} \mathrm{p/n} \mathrm{InGaAs} \mathrm{Monolithic}$ Interconnected Modules," Third NREL TPV Conference, 1997.

[3] -N.S. Fatemi, D. M. Wilt, P.P. Jenkins, R.W. Hoffman, V.G. Weizer, C.S. Murray, and D. Riley, "Materials and Process Development for the Monolithic Interconnected Module (MIM) InGaAs/InP TPV Devices", Third NREL TPV Conference, 1997.

[4] J. S. Ward, A. Duda, M.W. Wanlass, J.J. Carapella, X. Wu, R.J. Matson, T.J. Coutts, and T. Moriarty, "A Novel Design for Monolithically Interconnected Modules (MIMs) for Thermophotovoltaic Power Conversion," Third NREL TPV Conference, p. 227, 1997.

[5] D. M. Wilt, N. S. Fatemi, P.P. Jenkins, R.W. Hoffman, G.A. Landis, and R.K. Jain, "Monolithically Interconnected InGaAs TPV Module Development," Twenty fifth Photovoltaic Specialists Conference (PVSC), 1996.

[6] S. Wojtczuk, "Comparison of $0.55 \mathrm{eV}$ InGaAs Single-Junction vs. Multi-Junction TPV Technology," Third NREL TPV Conference, 1997.

[7] M.B. Clevenger, C.S. Murray, and D.R. Riley, "Spectral Utilization in Thermophotovoltaic Devices," Materials Research Society (MRS) Fall Meeting, Boston, MA, December 1997.

[8] Data presented by Knolls Atomic Power Labs (KAPL) in a review meeting held in Schenectady, NY, January 1998.

[9] C.T. Ballinger, et al., "Monte-Carlo Analysis of a MIM Device with a Back Surface Reflector," Proceedings $4^{\text {th }}$ NREL TPV Conference, AIP, 1998.

[10] G.W. Charache, J.L. Egley, L.R. Danielson, D.M. Depoy, P.F. Baldasaro, B.C. Campbell, S. Hui, L.M. Fraas, and S.J. Wojtczuk, "Current Status of Low-Temperature Radiator TPV Devices", Twenty-fifth IEEE PVSC, p.137, 1996. 